\title{
Leadership Orientation of Afghan and Japanese Respondents: A Study of “Guzaara” or Getting Along in
} Asia

\author{
Bahaudin G. Mujtaba \\ Nova Southeastern University, College of Business and Entrepreneurship, USA \\ mujtaba@nova.edu
}

\begin{abstract}
The purpose of this paper is to analyze the leadership tendencies of Afghan and Japanese respondents by exploring their task and relationship orientations. While there are many published studies on the Japanese work culture and leadership practices, research about Afghan working adults is limited. Using the Style Questionnaire, this research collected and compared the leadership orientations of 400 respondents from each country based on national culture on the task and relationship-orientation continuums. To deepen the understanding of Afghan leadership tendencies, we explore their culture of "guzaara" (getting along) practices. Similarly, we discuss the Japanese concept of "ba" (interactive knowledge creation) as one example of a best practice that can be benchmarked by others in society. Both Afghanistan and Japan are high-context cultures; therefore, people are expected to be more relationship-oriented. While respondents from both countries do have a stronger focus on their relationships, data shows that Afghans have a significantly higher score on both the task-orientation as well as relationship-orientation continuums, compared to their Japanese counterparts. Implications, recommendations and limitations of the study are provided. The findings that Japanese and Afghan employees are indeed focused on their relationships, and that they have a moderately high task orientation scores, are useful for managers and expatriates working in these two Asian countries.
\end{abstract}

Keywords: Afghan leadership orientation; Japan cultural orientations; Guzaara; Edaara; Rahbariat; Ba; relationship-orientation; task-orientation.

\section{Introduction}

The leadership tendencies of modern managers and working professionals can be researched using their task and relationship orientations. To explore the behavioral tendencies of working adults in the Afghan and Japanese workplaces, we review the traditional norms of each country's rich cultural practices while assessing their leadership similarities and differences. The Afghan and Japanese cultures both have a rich history with strong traditions and norms which provide good learning opportunities for application in the modern workplace (Huang, Mujtaba, Cavico, and Sims, 2006; Scagliotti and Mujtaba, 2010; Molz and Mujtaba, 2011; Mujtaba and Isomura, 2012; Nguyen, Mujtaba, Tran, and Rujis, 2013; Nguyen, Mujtaba, \& Pham, 2013). Due to economic and corporate trends like mergers and acquisitions (M\&A) over the past few decades, there have been significant changes in Japan (Jackson and Miyajima, 2007; Economic and Social Research Institute, 2010; Yoshitomi, 2011). Consequently, more and more foreigners are travelling to Japan to learn and work in Japanese organizations (Molz and Mujtaba, 2011). As such, Olcott (2009) suggests that Japanese companies must be ready to role model and teach their traditional management and leadership practices when they are integrated with so many expatriates or foreigners. Therefore, understanding the leadership orientations of the Japanese is increasingly more important for global leaders (Schneider and Littrell, 2003; Mujtaba and Isomura, 2012).

This presents great learning opportunities for Afghans to learn from the successes of the Japanese in developing their own economy since both cultures seem to have similar cultural orientations. Afghans and Japanese are likely to be strongly relationship-oriented because their cultures are collectivistic. Research has demonstrated that Japan is a group-oriented culture, long-term oriented, and a high context society (Nakane, 1967; 1970; Hall, 1976; Ouchi, 1978; 1980; and Hofstede, 1980; 1991). Similarly, Japanese companies tend to form long-term relationships among their colleagues and partners in business (Ouchi, 1978; 1980; 2004; Nonaka, 1988; 1995; 1998; Asanuma, 1989; Aoki, 1990; and Badaracco, 1991). Afghans can learn from these Japanese concepts to improve their work environment and economy, since there are links and connections between cultural leadership practices and performance (Misumi and Seki, 1971; Misumi, 1986; Mujtaba, Tajaddini, and Chen, 2011; Mujtaba, 2014; Hughes, Ginnett, and Curphy, 2019). It is true that Japanese change and adapt their leadership tendencies over time and with changing conditions since employment stability is 
no longer guaranteed as the rate of unemployment has been steadily increasing in Japan (Abegglen, 1958; Minister of Health, Labor and Welfare, 2010b; 2010c; Japan Institute for Labor Policy and Training, 2005).

Accordingly, the Japanese pay system has shifted from a seniority-based system to performance-based systems despite the fact that seniority-based pay system is thought to be dominant (Mujtaba and Isomura, 2012). Moreover, Japan's employee-based corporate governance is in transition, and the influence of shareholders is rising (Abe and Shimizutani, 2005). Japanese management, leadership practices and behavioral tendencies have become more performance-oriented (Jackson and Tomioka, 2004). Nonetheless, some deeply rooted Japanese management practices not changed much despite the fact that they are more open to the global world (Holzhausen, 2000; Kono and Clegg, 2001; Matsuura et al., 2003; Rebick, 2005; Abegglen, 2006; and Witt, 2006). In the remaining parts of the paper, we review literature on traditional leadership as well as the various management styles of managers in Afghanistan and Japan, along with their cultural norms. Then, we explain the methodology, hypotheses, and overall results. Finally, we discuss the implications, limitations and conclusions of the study.

\section{Leadership Orientations}

Leadership is a science as it can be at least partially quantified and documented as a study, and it is an art since one can get better at it through experience over time (Hughes, Ginnett, and Curphy, 2019; Mujtaba, 2019). Responsible managers must gain experience and learn on a continuous basis (Syed and Kramar, 2009; Prahalad, 2010). Regardless of the controversy of it being a science or an art, Barnard (1948) explains that leadership is a function of at least three complex variables: the leaders, the followers, and the situational conditions. Consequently, leadership is a complicated process which requires both artistic and scientific skills. Bass (1990) pointed out that the focus of research has shifted from leaders to their relationships with the followers, and then to the interaction between the leaders and situational or cultural conditions. Hofstede (1980) and Trompenaar (1993) emphasized that culture plays an important role in the behavior of its people. Moreover, according to Adler (1986), national culture has a greater impact on employees than the organization's culture. Thus, management concerns itself not only with optimizing organizational culture but also with developing relevant management practices and skills that are aligned with the national culture of each country. Japan is a high-context culture with a homogenous population who are collectivistic and highly group-oriented. Similarly, the Afghan culture is high-context, collective, and group-oriented but heterogeneous in terms of language, ethnic background, religion, and even physical appearance.

Thomas and $\mathrm{Au}$ (2002) explain vertical collectivism as a practice where individuals see themselves as a part of an in-group where there are differences in status. Therefore, to avoid cultural bias, we must pay attention to the details of culture. Actions and behaviors are basically context specific; hence, a better understanding of subtle nuances and mechanisms by which culture works is required (Dorfman and House, 2004). To understand the cultural influence on leadership, we should pay attention to the details of people's behaviors by examining the internal factors' impact on leadership tendencies (Lincoln, 1987; Dorfman and House, 2004; Fukushige and Spicer, 2007). In the leadership literature, the behaviors of leaders are discussed in terms of initiating structure (task-orientation) and consideration (relationship-orientation) components (Halpin and Winer, 1957; Fleishman, 1967). Bass (1990) found relationship-oriented functions to be associated with subordinate satisfaction, and task-oriented functions are linked with performance. Similarly, the relationship function is positively associated with group performance. Overall, situational leadership theory states that the best leadership style depends on the variables surrounding each decision, person, and strategy. One dimension of each person's leadership style is the extent to which he or she is people-oriented or taskoriented. Since cultures influence people through years of socialization, this study will aid in determining whether people of high-context culture are more relationship-oriented or more task-oriented. Thus, it is appropriate that we approach leadership practices of Afghan and Japanese from the perspectives of task and relationship orientations.

The Afghan Culture: Afghanistan is a small country located in South Asia. Afghanistan in the northwest of the Indian subcontinent is surrounded by Tajikistan, Uzbekistan, at Turkmenistan at the Amu River, on the east and south by Pakistan, in the northeast by the Republic of China, and on the west by Iran. Afghanistan has an 
approximate population of 36 million people and literacy rate is about 30 percent. About 80 percent of Afghans have no formal schooling experience due to the poor economy, lack of proper security, and several decades of war. Consequently, people are informally conditioned by the cultural norms such as guzaara (getting along and people-orientation) and edaara (managing and task-orientation) throughout their lives, especially during their socialization as young children, in hopes that they grow up to become effective rahbars (leaders).

Leadership requires influencing others while providing an environment where organizational objectives can successfully be achieved (Kaifi, Mujtaba, and Xie, 2009; Mujtaba and Kaifi, 2010). Afghans believe that effective leadership (or rahbariat) requires good human skills (guzaara) and technical skills (edaara) while a person exerts influence over one or more individuals to inspire, motivate, and direct their behaviors toward the achievement of organizational goals. The individual or person who exerts any form of influence that guides behavior is the leader (rahbar). In the behavioral perspective of leadership, there are two clusters of behaviors discussed that focus on the people and tasks. First, people-oriented behaviors (guzaara) include showing mutual concern, trust and respect for others. People-oriented leadership tends to result in higher job satisfaction among subordinates, as well as lower absenteeism, grievances, and turnover compared to using task-oriented style. An unintended consequence or side effect of people orientation is that job performance tends to be lower than for employees with task-oriented leaders (Hersey and Campbell, 2004). Second, taskoriented leadership styles (edaara) generally include behaviors that define and structure work roles to ensure that everyone follows company rules in order to reach performance capacity and meet the established standards. An unintended consequence or side effect of task-oriented leadership is that it can result in lower job satisfaction as well as higher absenteeism and turnover among subordinates (Hersey, Blanchard, and Johnson, 2001). Behavioral leadership scholars conclude that some people are high or low on both styles, others are high on one style and low on the other, and most individuals are somewhere in between in the continuum (Hersey, 1984).

The key is to be a flexible leader and use whatever orientation or skill is best for a given situation (Mujtaba, 2014). Let us look at the Afghan concepts of guzaara, edaara, and rahbariat, which are important elements of management and leadership practices in Afghanistan. "Guzaara" is the willingness, attitude of peopleorientation, and skill to get by, get along, make ends meet, remain patient, think win-win, cooperate, avoid unnecessary risks, curbing one's indulgences, being sustainable, negotiable, and doing whatever is necessary to preserve important relationships. In reality, due to years of cultural conditioning, most Afghans become exceptional at "getting by," but some individuals do not always do well in "getting along." The word guzaara might be followed by "kaardan" which means "doing." In general, "guzaara kaardan" implies that one's actions should be aligned with and complementary to getting by, getting along, cooperating, and proceeding without being entangled into prolonged arguments. Overall, because of prolonged societal conditioning with guzaara, people are intrinsically conditioned not to always challenge higher-ranked and older individuals' opinions and practices. The two basic elements of guzaara can be "getting by" at the lower end, and "getting along" at the higher end of the continuum. The challenge for today's Afghan leaders and all working adults in Afghanistan is to cause a significant paradigm shift in the will and motivation of everyone in the country, through proper socialization and conditioning, so they can work on slowly making a transition from just "getting by" to actually "getting along" in today's interdependent global world. "Edaara" is having the ability to manage effectively, control, discipline, and keep order while expertly performing specific tasks (taskorientation). It is about the application of existing or applicable laws, norms, and effective people management skills.

It is about correcting personal performance problems and misbehaviors while managing each situation in a structured manner toward excellence. Once again, using edaara skills, it is important to develop and encourage Afghans to think critically and transition from "getting by" to "getting along" through strategic planning, collaborations, and effective leadership (rahbariat). While most Afghans learn to work well with different people groups and build trusting relationships for "getting by" through guzaara kaardan, it is time for them to move beyond it to "getting along" using their accumulated technical expertise, discipline, organizing, controlling, and task-orientation skills which are all important elements of effective edaara kaardan. "Rahbariat" (leadership) is the ability to lead, decide, and act by diagnosing the root causes of 
problems while separating them from the effect. Rahbariat is one's conceptual skill to think critically and strategically plan for the long-term using a balance of relevant guzaara and edaara kaardan skills. "Rahbariat" is the ability to differentiate between causes and effects or symptoms, while focusing on the long-term. It is about thinking critically to avoid the unintended negative consequences of societal conditioning on each decision and action. There are individuals who are excellent in the implementation of edaara skills (taskorientation), but not necessarily good in guzaara (people-orientation). Similarly, there are individuals who are excellent in guzaara skills (people-orientation), but not necessarily good in edaara (task-orientation). Effective leaders are those individuals who are excellent in both the skills of guzaara (people-orientation) and edaara (task-orientation) in a balanced manner and use whichever skill is needed the most at any given situation. As such, guzaara and edaara are closely aligned with the concept of situational leadership.

As espoused by Drs. Paul Hersey and Kenneth Blanchard, where one has to decide whether he or she needs to be more or less relationship-oriented or more or less task-oriented depending on the specific needs of those who are being influenced. One can be a good professional manager and leader by learning the concepts of guzaara, edaara, and proper rahbariat in order to better serve his or her colleagues, employees and the people of the world. Ultimately, effective leadership (rahbariat) is about the successful implementation and achievement of guzaara and edaara through a balanced application approach based on the needs of the situation and the readiness of followers or employees (see Figure 1). For example, when an employee is unable, unprepared, and/or demotivated to complete a task or job by himself or herself, then the manager should lead by example while being high on edaara orientation to explain the task and monitor each activity (low guzaara and high edaara). This means that the manager must be "hands on" and/or provide on-the-job training.

It also implies that the manager or trainer explicitly tells the worker what needs to be done, how it should be done, shows how the work is done through step-by-step explanations, and explains the expected standards. However, when the employee is not skilled in performing the task but he or she is motivated to learn and do the job, the manager should explain, mentor, supervise, and closely coach the worker to make sure the activity is completed in a timely manner based on the expected standards (high guzaara and high edaara). On the other side, the manager should attempt to be high on guzaara skills to build a strong relationship by participating with employees who know how to do the job successfully but lack confidence or motivation (high guzaara and low edaara). Finally, managers should lead using low levels of guzaara and edaara with employees who have successfully completed the job in the recent past and are motivated to perform the job; in such cases, one should properly delegate the job, set deadlines, and periodically monitor results by providing relevant feedback as needed.

Figure 1: Leadership (Rahbariat) Continuum




No management or leadership model is perfect; thus, they all have strengths and weaknesses. Educators and managers must focus on the strengths of each model, while circumventing or reducing the negative impact of its weaknesses. In the spirit of continuous improvement or the Japanese concept of "kaizen", since the culture of Japan and Afghanistan are similar in many respects, the Japanese culture and leadership practices should be explored for benchmarking and the development of Afghan managers.

Cultural Dimensions: Cultures regularize human behavior, thereby making decisions more predictable. Culture plays an important role in acting as moral leaders and being perceived as ethical managers locally, nationally and globally (Sanyal, 2005). Culture is "The collective programming of the mind which distinguishes the members of one human group from another. Culture, in this sense, includes systems of values; and values are among the building blocks of culture" (Hofstede, 1980, p. 21). The six value dimensions of national culture as identified by the Hofstede's framework for assessing cultures are:

Power Distance: The degree to which people accept that power in institutions and organizations is distributed unequally.

Individualism versus Collectivism: Individualism is the degree to which people prefer to act as individuals rather than as members of groups and believe in individual rights above all else. Collectivism emphasizes a tight social framework in which people expect others in groups of which they are a part to look after them and protect them.

Masculinity versus Femininity (achievement vs. nurturing): Masculinity is the degree to which the culture favors traditional masculine roles such as achievement, power, and control as opposed to viewing men and women as equals. A high femininity rating means the culture sees little differentiation between males and female roles and treats women as the equals of men in all respects.

Uncertainty Avoidance: The degree to which people in a country prefer structured over unstructured situations defines their uncertainty avoidance.

Long-Term versus Short-Term Orientation: People in a culture with long-term orientation look to the future, value thrift, persistence, and tradition. In a short-term orientation, people value the here and now; they accept change more readily and do not see commitments as impediments to change.

Indulgence versus Restraint: Indulgence societies tend to allow gratification of natural human desires related to enjoying life and having fun. Restraint societies tend to believe that gratification needs should be curbed and regulated by strict norms.

Geert Hofstede added the last dimension in 2010. Indulgent cultures tend to focus more on individual happiness, wellbeing, leisure time being more important, and there are greater freedom and personal control. In restraint cultures, positive emotions are less freely expressed and happiness, freedom and leisure are not given the same importance. Indulgent cultures tend to place more importance on freedom of speech and personal control while in restrained cultures there is a greater sense of helplessness about personal destiny. In indulgent cultures, such as USA, the expectation is that customer service employee should demonstrate their 'happiness' with a smile along with a friendly demeanor. However, in more restrained cultures such as Russia or eastern European countries this might be considered inappropriate and/or unnatural. Indulgence versus restraint dimension might have an impact on generational differences as the impact of technology on younger generations would suggest that the need for instant gratification is becoming more prevalent. 
Figure 2: Japan Cultural Dimensions Scores

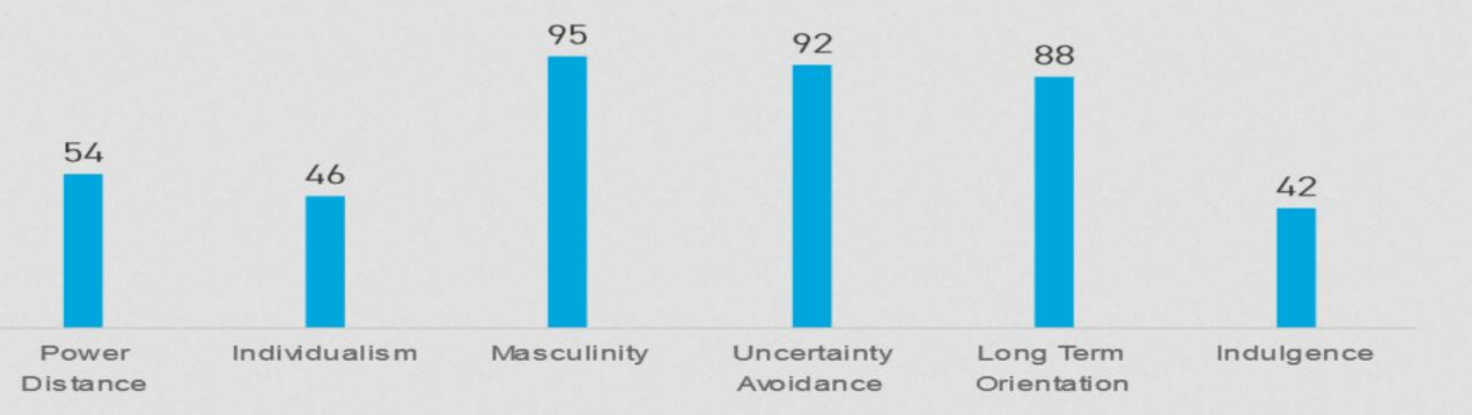

(Retrieved on February 2, 2019 from: https://www.hofstede-insights.com/)

As can be seen from Geert Hofstede's $(1980 ; 1991)$ cultural dimensions, power distance and individualism in Japan are in the medium range; masculinity, uncertainty avoidance and long-term orientation are in the high range, while indulgence is also in the medium range (see Figure 2). While there is no published research data based on Hofstede's cultural dimensions as of yet for Afghanistan, there are some excellent explanations that have been by researchers (Entezar, 2008). In general, power distance between workers and managers is likely to be very high for Afghans since formal position title and rank tends to have a high level of importance both on the job and in the community. Similarly, masculinity and uncertainly avoidance are high in Afghanistan as the concept of guzaara conditions people to "play it safe" and not take too much risk. While Afghans do put their faith into God and, therefore, some authors believe that they have low uncertainty avoidance tendencies (Entezar, 2008). However, Afghanistan as a country is a culture of cautious optimists and calculated risk-takers; consequently, most people avoid unnecessary uncertainty and risk. As a society, Afghans learn early on to "reach for the stars"; as such, they are highly achievement oriented.

On the other side of the continuum, individualism and long-term orientation are in the medium range. Finally, Afghan's indulgence score is likely to be in the low range since people are conditioned by the local norms of high uncertainty avoidance as well as other cultural traditions to avoid extravagant expenditures and to save for a "rainy" day (see Table 1). Due to the collective nature of people in Afghanistan and history of tribalism, most individuals learn to socialize and respect members of the community, especially their elders. While Afghans do restrain themselves from acting upon their impulsive indulgences, most of their decisions are short-term oriented as the years of political instability, widespread corruption, and ethnic conflicts have conditioned many toward a survival mode.

Table 1: Cultural Dimensions Range for Afghans and Japanese

\begin{tabular}{lll}
\hline Cultural Dimensions & Japan & Afghanistan \\
\hline Power distance & medium & Very high \\
Individualism & medium & medium \\
Masculinity & high & high \\
Uncertainty avoidance & high & Very high \\
Long term orientation & high & medium \\
Indulgence & medium & low \\
\hline
\end{tabular}

Japanese Culture: Hall (1976) divides culture into two extreme types: high context and low context cultures. In high context cultures, people share their way of thinking, feeling, and acting; therefore, they often use nonverbal communication. On the contrary, in low context cultures people utilize verbal communication. Japan, similar to Afghanistan, is a high context society. This partially explains why the Japanese and Afghan people tend to avoid uncertainty and why they are long-term and medium-range oriented. Japanese people try to build strong and stable relationships with others; as such, because of their high-context and homogenous culture, people can more effectively communicate with each other. Nakane (1970) explains that the group orientation of the Japanese is linked to the immediate social context called frame. Frame is circumstantial, a locality, and a particular relationship that binds like-minded colleagues into a group or clique. Frame is 
translated from the Japanese word, $b a$. Ba means into location or field. The dependence on frame produces a strong sense of belonging for the Japanese, a deeply emotional involvement of people, a strong sense of exclusiveness, and an emphasis on tangible interactions.

Consequently, according to Whitewill and Takezawa (1968) and Takezawa and Whitewill (1981), Japanese workers have high levels of work effort, organizational involvement and cooperation, acceptance and trust in management policies and practices. According to Ouchi (1978), Japanese organizations have evolved in a society in which individual mobility is traditionally low and where the culture supports norms of collectivism. In general, Japanese prefer staying in one company and enjoy long length of employment. Consequently, employees will be more familiar with the norms of the organizations and are more likely to develop strong friendships among their co-workers. Moreover, employees become integrated into the culture of the organization and this is a positive element for long-term sustainability (Wolf and Mujtaba, 2011). As such, Japanese organizations are like clans. Clans basically control an organization by socializing and conditioning its members toward a common vision. There are also inter-organizational connections in Japan, known as keiretsu. Each keiretsu is an interdependent collection of firms integrated as one collective enterprise or family of member companies, each connected to the others by various means.

The companies within the keiretsu help each other economically by buying shares of stock in each of the member firms. While the size of a keiretsu can be inclusive of over 100 members, each firm within it remains independent. Ouchi (2004) insists that organizational culture plays an important role in harmonizing individual and organizational goals in a large-sized organization. Japanese managers have a homogeneous value system and that both organizational and personal achievement goals are more behaviorally relevant than for North American and European managers (England, 1975; 1983). Japanese have developed their organizations and management styles on the basis of long and stable relationships (Goffee and Jones, 1996). Utilizing two dimensions, that is, solidarity and sociability, Goffee and Jones divide four types of organizational culture: communal, mercenary, networked, and fragmented. Solidarity is a measure of a community's ability to pursue shared objective quickly and effectively; meanwhile, sociability is a measure of sincere friendliness among members of a community. We can say that Japanese organization is the networked organization: high sociability and low solidarity (Mujtaba and Isomura, 2012).

Maintaining health relationships in a group is a top priority in Japan; consequently, leaders tend to avoid stressful disagreements and try to effectively manage dysfunctional conflicts in their organizations as quickly as possible (Nakane, 1970). To avoid conflicts in formal meetings, the leader and their followers exchange their opinions informally (Xu, 1987). After negotiating and reaching consensus, formal decisions are made. Generally, the manager will not decide until followers who will be affected have had sufficient time to offer their views, feel they have been fairly heard, and are willing to support the agreed-upon decision even though they may feel that it is not the best one (Ouchi, 1976; 308). This way of communication to build consensus is called "nemawashi"; and it is formally institutionalized as "Ringi sytem": where approval is recorded in a document and final decisions are escalated to the next higher level of management (Yamada, 1985; Ogata and Sanada, 1994; Porter et al., 2000; Haghirian, 2010). Thus, the leader is expected to spend much energy and time in acquiring his or her colleagues' agreement, approval and consent. According to Kono and Clegg (2001), about $70 \%$ of the organizational presidents in Japan adopt the consensus style of leadership.

Japanese managers try to harmonize the interests of all relevant groups in the organization. Haghirian (2010) emphasizes that Japanese leaders have more of a coordinating role than their Western counterparts. The role of leaders is to coordinate the interests of each fraction; leaders are obliged to get consent from each fraction, group or clique. Therefore, it takes time for leaders to make a final decision. The relationship between leaders and followers is based on protection and dependence. Doi (1973) emphasizes that dependence is strong in relationships of Japanese. In Japanese companies, middle managers play an important role in combining strategic macro information and hands-on micro information. The middle managers serve as the agents for change in the organization's self-renewal process. The middle managers deeply commit to their organization; therefore, they translate top management's vision into the operational level and support ideas created from the bottom. However, it is assumed that making strategic decisions is difficult, so this style of decision-making does not always adjust well or quickly to the modern and ever-changing business environment (Porter, 
Takeuchi and Sakakibara, 2000). Nonaka emphasizes that Japanese organizations create information by sharing not only explicit knowledge but also implicit knowledge among employees.

Nonaka and Konno (1998) consider " $b a$ " to be a shared space that serves as a foundation for knowledge creation. "Ba" is produced in the active interaction among people who share explicit and implicit knowledge (Nonaka and Takeuchi, 1995). Leaders are expected to be representatives of their employees' agreed-upon decisions. Consequently, the leader's decisions are unchangeable, thus, people are often forced to obey blindly under informal pressure (Tobe, Teramoto, Kamata, Sugiono, Murai, and Nonaka, 1984). Generally, the middle managers accept and support ideas from the bottom; so Japanese leadership style seems to be basically participative and democratic. On the other hand, as explained in the study by Mujtaba and Isomura (2012), once the decisions are made and come from the top, everyone would have to agree without any objections; so the leader's decisions look absolute and, at times, Japanese leadership style seems to be autocratic or directive. To sum up, the role of leaders in Japan is to maintain long-term relationships, coordinate activities, and authorize their decisions to implement them effectively. Japanese leadership tends to be more relationship and consideration-oriented. Japanese managers' leadership style also has an intermediate form between autocratic and democratic as well as directive and participative approaches (Mujtaba and Isomura, 2012).

\section{Methodology}

Paul Hersey (2008), states that leadership is the process of influencing others to achieve organizational objectives. Leaders use various amounts of task and relationship behaviors to achieve their goals. Task behavior (edaara) is the extent to which leaders engage in top-down communication by explaining what the follower is to do, as well as when, where, and how each function is to be accomplished; and relationship behavior (guzaara) is the extent to which leaders engage in joint communication with followers while providing socio-emotional support (Hersey, 2008). In this study, we used the Style Questionnaire to assess the leadership orientation of respondents. Northouse (2007) provides the Style Questionnaire to obtain a general profile of a person's leadership behaviors associated with the task and relationship orientations. This instrument was selected due to its short sentences and simplicity for use in a cross-cultural environment. The short statements leave little room for misinterpretations. The results can show one's use of various task and relationship behaviors. The statistical output for the reliability data has shown that the Cronbach's alpha is 0.887, which means that the questions are good for classroom test.

They are acceptable in social science research (Mujtaba and Balboa, 2009; Mujtaba, Afza, and Habib, 2011; Mujtaba and Isomura, 2012; Nguyen, Mujtaba, Tran, and Rujis, 2013; Nguyen, Mujtaba, \& Pham, 2013). To determine one's personal leadership characteristics, the respondent circles one of the options that best describe how he or she sees himself or herself (or the person that is being evaluated) regarding each statement. For each statement, the person indicates the degree to which he or she (or the person being evaluated) engages in the stated behavior. A rating of 1 means "never" and a rating of 5 means "always" with the person demonstrating the specific behavior to determine one's scores for the leadership styles questionnaire, one can add the responses for the odd-numbered items to determine the score for taskorientation behaviors, and add the responses for the even-numbered items to determine the score for relationship-orientation behaviors. The scoring interpretation for the Style Questionnaire by Northouse (2007, p. 87) is presented in Table 2.

\section{Table 2: Task and Relationship Score Interpretations}

\begin{tabular}{ll}
\hline $45-50$ & Very high range \\
$40-44$ & High range \\
$35-39$ & Moderately high range \\
$30-34$ & Moderately low range \\
$25-29$ & Low range \\
$10-24$ & Very low range \\
\hline
\end{tabular}


What is important to note is that effective leaders stay in control by managing through a balance of both task (edaara) and relationship (guzaara) oriented behaviors, as appropriate, to make sure the objectives and goals are accomplished in a timely manner. This study targeted Afghan and Japanese citizens, workers and managers. To increase both accuracy and response rate, the original questionnaire was translated into the Japanese and Persian languages so that those who were not fluent in English could easily respond to each question. The Japanese and Persian versions of the survey were back-translated into English, by two other individuals, to confirm their accuracy with the original instrument. The printed surveys were offered in Japan and Afghanistan to individuals who volunteered to complete it. Data shows that Japanese males are more task-oriented compared to their Japanese female counterparts; however, the relationship orientation scores of male and female were similar. The online version of the survey was only available in English. The surveys were distributed and collected physically and sent electronically to working adults, graduate students, colleagues, and friends who live all around the globe. The self-administered questionnaire offered anonymity, which is important when conducting research related to leadership and management characteristics.

Research Hypotheses: The research question for this study was to determine whether Afghan and Japanese respondents have similar or different scores on the relationship orientation (guzaara) and task orientation (edaara) dimensions of leadership. The specific hypotheses for this study are as follows:

Hypothesis 1: Afghan respondents will have similar scores for relationship and task orientations.

Hypothesis 2: Japanese respondents will have similar scores for relationship and task orientations.

Hypothesis 3: Afghan and Japanese respondents will have similar scores on task orientation.

Hypothesis 4: Afghan and Japanese respondents will have similar scores on relationship orientation.

For the purpose of this study, a convenient population was sampled and most data was collected electronically for analysis. From the collected data, 400 candidates were selected for analysis. The convenience sample was obtained through educational organizations, businesses and entrepreneurs, private and public sector institutions. Overall, the findings of this research are consistent with previous studies conducted with Japanese working adults (Mujtaba and Isomura, 2012), and Afghan respondents in Kabul, Herat, and others around the country (Mujtaba and Sadat, 2010; Mujtaba and Kaifi, 2010). A paragraph explaining the purpose of this research and guaranteeing confidentiality was included with the survey. The respondents were asked to voluntarily complete the questionnaire. Out of total surveys selected for both Afghan and Japanese respondents, $30 \%$ are female respondents and $70 \%$ are males.

\section{Task and Relationship Orientation Results}

The result of data analysis demonstrates that Afghans are highly task-oriented and highly-relationshiporiented. While the average score of Afghan respondents for task orientation (edaara) falls in the "high range," and their relationship orientation (guzaara) average also fell in "high range", there are statistically significant differences among them. In other words, Afghan respondents in this study demonstrated a significantly high focus on both guzaara and edaara dimensions of leadership.

Table 3: Afghan Task vs. Relationship Orientations

\begin{tabular}{ll}
\hline Hypothesized Difference & $\mathbf{0}$ \\
\hline Level of Significance & 0.05 \\
Task Orientation & \\
Sample Size & 400 \\
Sample Mean & 41.0825 \\
Sample Standard Deviation & 7.353 \\
Relationship Orientation & \\
Sample Size & 400 \\
Sample Mean & 43.87 \\
Sample Standard Deviation & 6.523
\end{tabular}


Intermediate Calculations

Pooled Variance

48.308069

Difference in Sample Means

$-2.7875$

t-Test Statistic

Two-Tailed Test

Lower Critical Value

$-1.963$

Upper Critical Value

1.963

p-Value

0.00000002

As can be seen from Table 3 and using the t-test for differences in the two means, at a 0.05 level of significance, the first hypothesis is rejected because the calculated $t$ value $(-5.67)$ does not fall within the critical value of $t$ for statistical significance; in other words, since the $t$ value does not fall within the critical values $(+1.96$ and -1.96), the alternative hypothesis is supported. Furthermore, since the p-value of 0.00000002 is smaller than alpha $(\alpha)=0.05$, there is sufficient evidence to reject the hypothesis. Therefore, it can be said that Afghan respondents have dissimilar scores for relationship and task orientations as they are more highly focused on their relationships. Based on the results, the task orientation and relationship orientation scores of Afghan respondents do not appear to be similar. As such, one can conclude that the Afghan respondents have significantly higher scores on the relationship orientation. Perhaps because of their guzaara socialization as well as high context and collective nature, Afghan respondents seem to be putting significantly more emphasis on their relationships. In other words, Afghan respondents in this study demonstrated a significantly higher focus on guzaara orientation, as compared to their edaara dimension of leadership. While the average score of Japanese respondents for task orientation falls in "moderately high range," their relationship orientation average falls in "moderately high range" as well; as such, there are statistically significant differences among them.

Table 4: Japanese Task vs. Relationship Orientations

\begin{tabular}{ll}
\hline Task Orientation & \\
\hline Sample Size & 400 \\
Sample Mean & 35.65 \\
Sample Standard Deviation & 7.21 \\
Relationship Orientation & \\
Sample Size & 400 \\
Sample Mean & 38.8 \\
Sample Standard Deviation & 5.58 \\
t-Test Statistic & -6.91 \\
Lower Critical Value & -1.963 \\
Upper Critical Value & 1.963 \\
p-Value & 0.00000000 \\
\hline
\end{tabular}

As can be seen from Table 4 and using the t-test for differences in two means, at a 0.05 level of significance, the second hypothesis is rejected because the calculated $t$ value $(-6.91)$ does not fall within the critical value of $t$ for statistical significance; the alternative hypothesis is supported. Furthermore, since the $\mathrm{p}$-value of 0.0000000 is smaller than alpha $(\alpha)=0.05$, there is sufficient evidence to reject the hypothesis. Therefore, Japanese respondents have dissimilar scores for relationship and task orientations as they are more highly focused on their relationships. Based on the results, the task orientation and relationship orientation scores of Japanese respondents do not appear to be similar. As such, one can conclude that the Japanese respondents have significantly higher scores on the relationship orientation. Perhaps because of their high context and collective nature, Japanese respondents seem to be putting significantly more emphasis on their 
relationships. Japanese appear to have moderately high scores in both their task and relationship orientations.

These results are similar to those of the Afghan respondents; it means that both Japanese and Afghan respondents demonstrate a significantly higher focus on their relationships, as compared to their taskorientation. Additional analysis confirmed that older and male Japanese are more task-oriented. As can be seen from Table 5 and using the t-test for differences in two means, at a 0.05 level of significance, the third hypothesis is rejected because the calculated $t$ value $(-10.52)$ does not fall within the critical value of $t$ for statistical significance. Also, since the p-value of 0.00 is smaller than alpha $(\alpha)=0.05$, there is sufficient evidence to reject the hypothesis. Therefore, Afghan and Japanese respondents have dissimilar scores for task orientation; Afghans have a significantly higher focus on the task orientation. This is a paradox as Afghans demonstrate a significantly higher task-orientation compared to their Japanese counterparts, yet the country of Afghanistan is far behind in terms of overall national productivity in relation to Japan.

Table 5: Japanese vs. Afghan Task Orientations

\begin{tabular}{ll}
\hline Japanese & \\
\hline Sample Size & 400 \\
Sample Mean & 35.65 \\
Sample Standard Deviation & 7.258 \\
Afghans & \\
Sample Size & 400 \\
Sample Mean & 41.0825 \\
Sample Standard Deviation & 7.353 \\
t-Test Statistic & -10.52 \\
p-Value & 0.000 \\
\hline
\end{tabular}

Table 6: Japanese vs. Afghan Relationship Orientations

\begin{tabular}{ll}
\hline Japanese & \\
\hline Sample Size & 400 \\
Sample Mean & 38.8 \\
Sample Standard Deviation & 5.58 \\
Afghans & \\
Sample Size & 400 \\
Sample Mean & 43.87 \\
Sample Standard Deviation & 6.523 \\
t-Test Statistic & -11.81 \\
p-Value & 0.000 \\
\hline
\end{tabular}

As can be seen from Table 6, the fourth hypothesis is rejected because the calculated t value (-11.81) does not fall within the critical value of $t$ for statistical significance; in other words, the alternative hypothesis is supported. Furthermore, since the p-value of 0.000 is smaller than alpha $(\alpha)=0.05$, there is sufficient evidence to reject the hypothesis. Therefore, Afghan and Japanese respondents have dissimilar scores for relationship orientation. Based on the results, the Afghan respondents have a significantly higher focus on relationship orientation. Perhaps because of their cultural socialization with guzaara and years of conflicts with foreign forces, Afghan respondents seem to be putting significantly more emphasis on their relationships. 


\section{Discussion, Implications and Suggestions}

It was hypothesized that Afghan and Japanese respondents will have similar scores for relationship and task orientations; however, this research did not support this hypothesis because both Afghans and Japanese are more highly focused on their relationships. In addition, older Japanese appear to be more task-oriented than their younger counterparts. This study's result supports literature review on Japanese culture, organization and management practices that the Japanese are relationship-oriented. Moreover, we can confirm that relationship orientation remains unchanged despite the fact that Japanese management practices might be adjusting to the global economic markets. Japanese are more relationship-oriented than task-oriented; however, their task orientation falls in the moderately high range as well. We can say that the result is related to the findings of Hofstede $(1980 ; 1991)$ that power distance is in the medium range and masculinity is in the high range. Global managers should pay attention to the reality that Japanese management practices are based on their relationship orientation and getting along with all relevant stakeholders through effective teamwork, participative decision-making and cooperation. While Afghans are highly focused on their relationship and task orientations, no significant differences were found based on gender or age. I do believe in the axiom that if you want to go fast, go alone, but if you want to travel far then goes together.

History has shown that over the last century Japan went very fast and very far in economically becoming one of the world's super powers. In this modern twenty-first century world, Japan is joining the world leaders to help other countries move along in the continuum of economic prosperity. Afghan leaders must take advantage of the rich Japanese experiences and assistance in travelling together toward a brighter future for everyone in the world. It is true that Afghans need to go fast and far simultaneously; with their cultural strengths in relationship orientation, they can build strong partnerships with other Asian cultures like Japan to help them progress successfully in their leadership and management practices. Learning and benchmarking leadership best practices can take place from any country or culture. There is an Italian proverb, which states, "After a game of chess, the King and the pawn go into the same box." The same is true for people as rich and poor, men and women, and people of developing and developed countries alike, end up leaving the world eventually. The hope for every leader is that between birth and death, we make a positive difference in the lives of those around us. Afghans should learn from their own positive and negative trends in the past, as well as the positive and negative patterns of other cultures and countries. As the proverb goes, those who do not know history are likely to repeat it. As such, we should learn from the past to positively influence our lives in the present and future. In any culture, influential leaders are ultimately responsible for establishing ethical strategies the country should implement in the present (Mujtaba, Tajaddini, and Chen, 2011) in order to create a better and ideal future.

It is very important in Afghanistan that leaders become ethical role models and deliver what they promise to others in the community, country, region, and society by reducing and eradicating the existence of mismanagement. It is the responsibility of all public officials and private sector leaders to be culturally competent, ethical role models. Every manager must be role models of guzaara, edaara, rahbariat and they should provide development opportunities for their employees and staff. It is a fact that specific training and educational programs can greatly enhance the level of human development and critical thinking. A bettereducated Afghan society is more likely to be responsible for critical thinkers and leaders. Effective critical thinkers are open-minded and self-directed as they discipline and monitor their own views before implementing a major decision. Critical thinkers purposely and explicitly go beyond their intuition or gut feelings to analyze and assess all the facts in a given situation so they can be consistently fair to all stakeholders in a decision. Critical thinkers live fair-mindedly while internalizing and promoting universal values. There are limitations to any academic study and there is no exception here. First, the small number of responses from a convenient population is one of them. Future studies should compare specific populations in different parts of each country with similar working backgrounds and demographic variables. While both Afghan and Japanese populations seem to have a significantly higher focus on the relationship orientation, this might be true simply because they understand the importance of maintaining good connections with others in society due to the economic necessities and not necessarily years of cultural socialization. 
Summary: This paper provided an overview of the culture and people of Afghanistan and Japan. The paper also discussed the Afghan culture's norm of guzaara or getting along which influences their relationshiporientation. Guzaara is an attitude of cooperating, getting along, showing restraint, win-win thinking, avoiding unnecessary risks, being sustainable, and doing whatever is necessary to preserve relationships and "save face". While the Japanese may not use the word guzaara in their language, their culture and daily behaviors seem fully aligned with this concept since it implies that one's actions should always be one of cooperating, getting along, and being sustainable. Today's global and competitive work environment, especially in developing economies such as Afghanistan, needs educated and strong leaders who think critically about their decisions. As such, since both countries have similar cultural orientations, Afghan leaders and managers can better educate themselves, by learning many of the relevant best practices, which have made Japan successful and apply them to their own country in Afghanistan. Researchers should also note that the quality of education might also be an important variable or factor in the scores of respondents. Therefore, future studies should test "education" to see if this is a significant variable in the task and relationship orientation scores of respondents in each culture. True leaders have the confidence to learn on a continuous basis, and then standalone with strong ethical convictions and high standards. Overall, this study explored the basic understanding of Afghan and Japanese leadership orientations based on quantitative research and also provided information for local and global managers about the mechanism of their behavior by more closely exploring the culture of guzaara or getting along in Afghanistan.

\section{References}

Abe, N. \& Shimizutani, S. (2005). Employment policy and corporate governance: an empirical analysis on the stakeholder model in Japan. ESRI Discussion Paper Series, No. 136, Economic and Social Research Institute, Cabinet Office, Tokyo, Japan.

Abegglen, J. C. (1958). Japanese Factory: Aspects of its Social Organization. Free Press: Glencoe, IL.

Abegglen, J. C. (2006). 21 $1^{\text {st }}$ Century Japanese Management. Palgrave Macmillan: New York.

Adler, N. J. (1986). International Dimensions of Organizational Behavior. Kent Publishing: Boston, MA.

Aoki, M. (1990). Toward an economic model of the Japanese firm. Journal of Economic Literature, 28(1), 1-28.

Asanuma, B. (1989). Manufacturer-supplier relationships in Japan and the concept of relation-specific skill. Journal of the Japanese and International Economics, 3(1), 1-30.

Badaracco, J. L. (1991). The Knowledge Link: How Firms Compete through Strategic Alliances. Harvard Business School Press: Cambridge, MA.

Barnard, C. I. (1948). The nature of leadership, in Organization and Management: Selected Papers. Harvard University Press: Cambridge, MA, 80-110.

Bass, B. M. (1990). Bass and Stogdill's Handbook of Leadership: Theory, Research, and Managerial Applications, $3^{\text {rd }}$ ed. Free Press: New York, NY.

Bass, B. M. \& Bass, R. (2008). The Bass Handbook of Leadership: Theory, Research, and Managerial Applications. Free Press: New York, NY.

Campbell, D. J., Bommer, W. \& Yeo, E. (1993). Perceptions of appropriate leadership style: participation versus consultation across two cultures. Asia Pacific Journal of Management, 10(1), 1-19.

Cavico, F. J. \& Mujtaba, B. G. (2011). Baksheesh or Bribe: Cultural Conventions and Legal Pitfalls. ILEAD Academy Publications; Davie, Florida, United States.

Doi, T. (1973). The Anatomy of Dependence. Kodansha International: Tokyo.

Dorfman, P. W. \& House, R. J. (2004). Cultural influences on organizational leadership. In House, R. J., Hanges, P. J., Javidan, M., Dorfman, P. W. \& Gupta, V. (Eds.), Culture, Leadership, and Organizations: The GLOBE Study of 62 Societies. Sage: Thousand Oaks, CA.

Economic and Social Research Institute. (2010). Naigai M\&A jijo chousa kenkyu hokoku 2010 (M\&A conference report 2010).

England, G. W. (1975). The Manager and his Values: An International Perspective. Ballinger: Cambridge, MA.

England, G. W. (1983). Japanese and American management: Theory Z and beyond. Journal of International Business Studies, 14(2), 131-42.

Entezar, E. (2008). Afghanistan 101: Understanding Afghan Culture. Xlibris Corporation: United States.

Fleishman, E. A. (1967). Development of behavior taxonomy for describing human tasks: a correlationalexperimental approach. Journal of Applied Psychology, 51(1), 1-10. 
Fukushige, A. \& Spicer, D. P. (2007). Leadership preferences in Japan: an exploratory study. Leadership \& Organization Development Journal, 28(6), 508-30.

Goffee, R. \& Jones, G. (1996). What holds the modern company together? Harvard Business Review, November-December, 133-148.

Haghirian, P. (2010). Understanding Japanese Management Practices. Business Expert Press: New York, NY.

Hall, E. T. (1976). Beyond Culture. Anchor Books: New York, NY.

Halpin, A. W. \& Winter, B. J. (1957). A factorial study of the leader behavior descriptions Bureau of Business Research. Ohio State University, Research Monograph, 88, 30-51.

Hersey, P. (2008). Personal Communication on Situational Leadership. One-week Train-the-Trainer Workshop by Dr. Hersey and facilitators of The Center for Leadership Studies, February 2008, Escondido, CA. Phone: (760) 741-6595.

Hersey, P. (1984 \& 1997). The Situational Leader. The Center for Leadership Studies: Escondido, CA.

Hersey, Paul. \& Campbell, Ron. (2004). Leadership: A Behavioral Science Approach (Book). The Center for Leadership Studies: Escondido, CA. ISBN: 0-931619-09-2

Hersey, P., Blanchard, K. \& Johnson, D. (2001). Management of Organizational Behavior. Eight edition. Prentice Hall. ISBN: 013-032518X.

Hill, C. W. \& Hult, G. T. (2017). International Business. New York: McGraw Hill Education.

Hofstede, G. (1991). Culture and Organizations: Software of the Mind. McGraw-Hill: New York, NY.

Hofstede, G. (1980). Culture's Consequences: International Differences in Work-Related Values. Sage: Beverly Hills, CA.

Holzhausen, A. (2000). Japanese employment practices in transition: promotion policy and compensation systems in the 1990s. Social Science Japan Journal, 3(2), 221-35.

Huang, C., Mujtaba, G. B., Cavico, F. \& Sims, R. L. (July 2006). Ethics and Executives: A Cross-Cultural Comparison of Japan, Taiwan, and the United States. International Business and Economics Research Journal, 5(7), 9-22.

Hughes, R. L., Ginnett, R. C. \& Curphy, G. J. (2019). Leadership: Enhancing the Lessons of Experience, ninth edition. McGraw Hill: New York.

Jackson, K. \& Tomioka, M. (2004). The Changing Face of Japanese Management. Routledge: London.

Jackson, G. \& Miyajima, H. (2007). Varieties of capitalism, varieties of markets: Mergers and acquisitions in Japan, Germany, France, the UK and USA. RIETI Discussion Paper Series, 07-E-054.

Kaifi, B., Mujtaba, B. G. \& Xie, Y. (2009). The Perception of Afghan-American Leaders' Role in Economic Development Efforts in Afghanistan: A Study of Gender Differences and Repatriation to the Motherland. Journal of Diversity Management, 4(3), 35-46.

Nonaka, F. \& Kano, T. (1998). The end of lifetime employment in Japan? Evidence from National Surveys and field research. Journal of the Japanese and International Economics, 15(4), 489-514.

Kono, T. \& Clegg, S. (2001). Trends in Japanese Management: Continuing Strengths, Current Problems and Changing Priorities. Palgrave: NY, New York.

Lincoln, J. R. (1987). Japanese industrial organization in comparative perspective. Annual Review of Sociology, 13, 289-312.

Matsuura, K., Politt, M., Takada, R. \& Tanaka, S. (2003). Institutional restructuring in the Japanese Economy since 1985. Journal of Economic Issues, 31(4), 999-1022.

Misumi, J. \& Seki, F. (1971). Effects of achievement motivation on the effectiveness of leadership patterns. Administrative Science Quarterly, 16(1), 51-59.

Misumi, J. (1986). The Behavioral Science of Leadership: An Interdisciplinary Japanese Research Program. University of Michigan Press: Ann Arbor, MI.

Molz, J. \& Mujtaba, B. G. (2011). Toyota's Strides for Quality and Continuous Improvement: Japanese Pioneers in Value Creation and Lean Management. Proficient: An International Journal of Management, 3(5), 7 19.

Mujtaba, B. G. (March 9-10, 2019). Leadership Orientation of Afghan and Japanese Respondents: A Study of "Guzaara" or Getting Along in Asia. ICESS Proceedings Book, 1, pp. 50-67. The 16 ${ }^{\text {th }}$ International Conference on Economics and Social Sciences (ICESS-2019). Meiji University, Nakano Campus, Nakano-Ku, Tokyo, Japan. Website: www.ifrnd.org

Mujtaba, B. G. (2014). Managerial Skills and Practices for Global Leadership. ILEAD Academy: Davie, Florida. 
Mujtaba, B. G. \& Isomura, K. (2012). Examining the Japanese leadership orientations and their changes. Leadership \& Organization Development Journal, 33(4), 401-420.

Mujtaba, B. G., Tajaddini, R. \& Chen, L. Y. (2011). Business Ethics Perceptions of Public and Private Sector Iranians. Journal of Business Ethics, 104(3), 433-447.

Mujtaba, B. G., Afza, T. \& Habib, N. (2011). Leadership Tendencies of Pakistanis: Exploring Similarities and Differences based on Age and Gender. Journal of Economics and Behavioral Studies, 2(5), 199-212.

Mujtaba, B. G. \& Kaifi, B. A. (2010). An Inquiry into Eastern Leadership Orientation of Working Adults in Afghanistan. Journal of Leadership Studies, 4(1), 36-46.

Mujtaba, B. G. \& Sadat, S. K. (2010). Leadership Knowledge of Local and Expatriate Afghans: Are They Leaning More toward Tasks or Relationships? Journal of Business Studies Quarterly, 1(3), 1-12.

Mujtaba, B. G. \& Balboa, A. (2009). Comparing Filipino and American Task and Relationship Orientations. Journal of Applied Management and Entrepreneurship, 14(2), 82-98.

Nakane, C. (1967). Kinship and Economic Organizations in Rural Japan. Athlone Press: London.

Nakane, C. (1970). Japanese Society. University of California Press: Berkeley, CA.

Nakane, C. (1974). Cultural anthropology in Japan. Annual Review of Anthropology, 3(1), 57-72.

Nguyen, L. D., Mujtaba, B. G., Tran, C. N. \& Rujis, A. (2013). Cross-culture management: an examination on task, relationship and work overload stress orientations of Dutch and Japanese working adults. International Journal of Strategic Change Management, 5(1), 41-58.

Nguyen, L. D., Mujtaba, B. G. \& Pham, L. N. T. (2013). Cross culture management: An examination on task, relationship and stress orientations of Japanese and Vietnamese. International Journal of Strategic Change Management, 5(1), 72-92.

Northouse, P. G. (2007). Leadership: Theory and Practice, $4^{\text {th }}$ ed. SAGE: Thousand Oaks, CA.

Ogata, T. \& Sanada, H. (1994). Ringi shisutemu wo chukaku toshita shin gyousei joho sisutemu (A new administration information system with Ringi systems as the core), Shingaku Giho, 93(435), 19-24.

Olcott, G. (2009). Conflict and Change: Foreign Ownership and the Japanese Firm. Cambridge University Press: Cambridge.

Ouchi, W. G. (1978). Markets, bureaucracies, and clans. Administrative Science Quarterly, 25(1), 129-41.

Ouchi, W. G. (1980). Type Z organization: stability in the midst of mobility. Academy of Management Review, $3(2), 305-14$.

Ouchi, W. G. (2004). An interview with William Ouchi. Academy of Management Executive, 18(4), 108-16.

Porter, M., Takeuchi, M. \& Sakakibara, M. (2000). Can Japan Compete? Basic Books: New York, NY.

Prahalad, C. K. (2010). The responsible manager. Harvard Business Review, 88(1), 36.

Rebick, M. (2005). The Japanese Employment System: Adapting to a New Economic Environment. Oxford University Press: Oxford.

Sanyal, R. E. (2005). Determinants of bribery in international business: the cultural and economic factors. Journal of Business Ethics, 59(1), 139-145.

Scagliotti, G. V. \& Mujtaba, B. G. (2010). Take a Bow: Culturally Preparing Expatriates for Doing Business in Japan. Journal of Comprehensive Research, 8(1), 71-87.

Schneider, J. \& Littrell, R. F. (2003). Leadership preferences of German and English managers. Journal of Management Development, 22(2), 130-148.

Syed, J. \& Kramar, R. (2009). Socially responsible diversity management. Journal of Management and Organization, 15(5), 639-651.

Takezawa, S. \& Whitehill, A. M. (1981). Work Way: Japan and America. Japan Institute of Labor: Tokyo.

Thomas, D. C. \& Au, K. (2002). The effect of cultural differences on behavioural responses to low job and satisfaction. Journal of International Business Studies, 33(2), 309-22.

Tobe, R., Teramoto, Y., Kamata, S., Sugiono, T., Murai. T. \& Nonaka, I. (1984). Sippai no honshitsu: Nihon gun no soshikiron teki kenkyu (The nature of failure: an organizational study on Japanese army. Diamond Sya: Tokyo.

Trompenaars, F. (1993). Riding the Waves of Culture: Understanding Diversity in Global Business. Irwin: New York, NY.

Whitewill, A. M. \& Takezawa, S. (1968). The Other Worker: A Comparative Study of Industrial Relations in the United States and Japan. East-West Center Press: Honolulu, HI.

Witt, M. A. (2006). Changing Japanese Capitalism: Societal Coordination and Institutional Adjustment. Cambridge University Press: Cambridge. 
Wolf, F. \& Mujtaba, B. G. (2011). Sustainability in Service Operations. International Journal of Information Systems in the Service Sector (IJISSS), 3(1), 1-20.

Xu, L. (1987). A cross-cultural study on the leadership behaviour of Chinese and Japanese Executives. Asia Pacific Journal of Management, 4(3), 203-209.

Yamada, Y. (1985). Ringi to nemawashi (Ringi system and consensus building). Kodansha: Tokyo.

Yoshitomi, Y. (2011). Kaigai M\&A no atarashi nagare (New trends of M\&A in foreign countries). MARR, 195, 10-16.

Acknowledgement: This presentation of this research at the conference in Japan was partially funded by the "Hersey/McCartney Endowed Faculty Support Fund". As such, special thanks go to the Dr. Paul Hersey family their support of this research through the "Hersey/McCartney Endowed Faculty Support Fund" at the College of Business and Entrepreneurship of Nova Southeastern University. 